\title{
Early Detection of Silent Hypoxia in Covid-19 Pneumonia Using Smartphone Pulse Oximetry
}

\author{
Jason $\mathrm{Teo}^{1}$ (D) \\ Received: 24 April 2020 / Accepted: 7 May 2020 / Published online: 19 June 2020 \\ (C) Springer Science+Business Media, LLC, part of Springer Nature 2020
}

The coronavirus 2019 (COVID-19) disease caused by the severe acute respiratory syndrome coronavirus 2 (SARSCoV-2), which was first reported in the city of Wuhan, China in late December 2019, has since become a global pandemic by March 2020 (WHO). There are now more than 2.6 million cases of COVID-19 affecting 210 countries and territories resulting in more than 183,000 deaths as of 22 April 2020 (Worldometer Report). The International Monetary Fund estimates that COVID-19 will cause USD \$9 trillion in global GDP losses leading to the worst economic downturn since the Great Depression (IMF).

Writing in the New York Times on 20 April 2020, Dr. Richard Levitan, an intubation specialist, highlighted that a significant number of hospital admissions not due to COVID-19 were actually found to be suffering from pneumonia due to COVID-19 upon having their chest X-rays taken [1], most with severely low oxygen saturation levels of only $50 \%$. He pointed out that unlike normal pneumonia, in which patients will feel chest pain and significant breathing difficulties, initially COVID-19 pneumonia causes oxygen deprivation that is difficult to detect since the patients do not experience any noticeable breathing difficulties, hence causing a condition which he terms as "silent" hypoxia. By the time COVID-19 patients realize they are short of breath, their conditions have already significantly deteriorated into moderate-to-severe levels of pneumonia. Analysis of COVID-19 pneumonia patients revealed that the virus initially attacks the lungs in a different way. The air sacs in COVID-19 patients' lungs do not fill with fluid or pus as in normal pneumonia infections but rather the virus only causes the air sacs to collapse, thereby reducing the

This article is part of the Topical Collection on: Mobile \& Wireless Health

$\triangle$ Jason Teo

jtwteo@ums.edu.my

1 Universiti Malaysia Sabah, Kota Kinabalu, Sabah, Malaysia oxygen levels that lead to hypoxia in these patients but still maintains the lungs' normal ability to expel carbon dioxide. Consequently, the still-efficient removal of carbon dioxide is the reason why COVID-19 patients do not feel shortness of breath in the initial stages of COVID-19 pneumonia.

Thus, the ability to detect this silent form of hypoxia in COVID-19 patients before they begin to experience shortness of breath is critical for preventing the pneumonia from progressing to a dangerous level. The key is to be able to detect this initial drop in oxygen saturation levels so that patients infected with COVID-19 who begin to suffer from pneumonia can be detected very early on and put on a treatment plan to prevent the lungs from deteriorating further. Consequently, early detection of COVID-19 pneumonia can prevent patients from having to be treated with highly invasive procedures such as intubation and mechanical ventilation, a procedure which currently results in an $80 \%$ mortality rate for COVID-19 patients.

Blood saturation levels can be easily and non-invasively detected using pulse oximeters. Normally, pulse oximeters can be purchased at a relatively affordable price without prescription at pharmacies and retail stores. However, the availability of pulse oximeters in the US has become extremely limited since the first case of COVID-19 was reported (Quartz).

However, it is still possible to perform this early detection of silent hypoxia in COVID-19 patients using smartphones. It has been shown that oxygen saturation readings measured using smartphones correlate highly with readings obtained using medical-grade pulse oximeters. Using a Samsung Galaxy S8 smartphone, Tayfur and colleagues compared pulse oximetry readings against two medical-grade devices commonly found in emergency rooms and reported correlations of between 96-99\% [2]. Additionally, smartphone-based pulse oximetry has been found to be particularly accurate when the oxygen saturation levels in the users are above 90\% [3]. Oxygen saturation in healthy patients range from $95-100 \%$, so the general public could use their smartphones to regularly take their own measurements conveniently at home and contact their health 
provider immediately should they notice a visible drop in their oxygen saturation of below $95 \%$.

This form of smartphone-based pulse oximetry may lead to a significant increase in the early detection of silent hypoxia, and hence identification of the onset of COVID-19 pneumonia. With the widespread availability of smartphones, this approach could increase the chances of detecting pneumonia in COVID-19 patients before severe infections set in to their lungs. This would almost certainly significantly reduce intensive care admissions, intubations, and the mortality rate of COVID-19.

Funding Information No funding was received for this work.

\section{Compliance with Ethical Standards}

Conflict of interests The author declares that he has no conflict of interest.
Ethical Approval This article does not contain any studies with human participants or animals performed by any of the authors.

\section{References}

1. Levitan, R., The Infection That's Silently Killing Coronavirus Patients (accessed 22 April 2020). https://www.nytimes.com/ 2020/04/20/opinion/coronavirus-testing-pneumonia.html, 2020.

2. Tayfur, İ., and Afacan, M. A., Reliability of smartphone measurements of vital parameters: A prospective study using a reference method. Am. J. Emerg. Med. 37(8):1527-1530, 2019.

3. Tomlinson, S., Behrmann, S., Cranford, J., Louie, M., and Hashikawa, A., Accuracy of smartphone-based pulse oximetry compared with hospital-grade pulse oximetry in healthy children. Telemedicine and e-Health 24(7):527-535, 2018.

Publisher's Note Springer Nature remains neutral with regard to jurisdictional claims in published maps and institutional affiliations. 